\title{
Did Dr Shah die in vain?
}

THREE years ago Dr V. H. Shah, a senior agronomist with the Indian Agricultural Research Institute (IARI), committed suicide in protest against the system prevailing in Indian agricultural research - and his was the third suicide of an agriculturalist in twelve years. His complaints, left in a letter to the director of IARI $\mathrm{Dr}$ Swaminathan, fell into two categories - first, that scientific results were being misrepresented to the extent that misleading and incorrect publicity was being disseminated; and second, that the career structure in agricultural research was being undermined by improper appointments. The failure of Dr Shah to be appointed to a professorship in agronomy was the immediate cause of his suicide, and in his letter he mentioned another appointment in agronomy which he also regarded as going to the wrong man.

Reaction was rapid. A committee of considerable eminence was established and reported in 1973. Since there were obviously more complaints in the air against the Indian Council for Agricultural Research (ICAR) than Dr Shah had spelt out, the committee investigated recruitment files and sent out questionnaires to a wide range of scientists.

To the accusation of scientific misrepresentation, the committee gave a mixed response. Dr Shah had named three specific cases, and in only one of the three did the committee go along with his accusation, although there were some sharp words on the way that advances in agricultural science were being publicised, and this criticism extended beyond the instances raised in the suicide note. The scientific issues have been rather extensively aired in New Scientist recently and need no further comment here.

The question of employment conditions and morale are, however, worth discussion. The committee unearthed much dissatisfaction and hard feeling within the agricultural community. This was directed at just about every aspect in their scientific life: appointments were said to be going to incompetents, library facilities were inadequate, there was too much power at headquarters, it was impossible to promote without there being a vacancy available (and competition for it) and equally impossible to get rid of incompetent workers. Perhaps most significantly, half the responses to the questionnaire on the question of what caused most difficulty in doing research blamed interference by supervisors.

The examining committee accepted the validity of much of this criticism. Indeed, the committee's own technical advisers themselves felt sufficiently strongly to write that the malaise which they had observed was not confined to ICAR, but "barring minor exceptions, pervaded the entire scientific and academic community of the country. At root, it is greed for bureaucratic power and love of a comfortable life which afflicts this class. Juniors are intellectually as corrupt as seniors, and politicisation of academic and scientific life makes matters much worse."

Ironically the committee were not so impressed by two of the cases brought forward by Dr Shah himself. They found that the appointment which he had himself hoped to secure and which went to someone else was unobjectionable. And whilst they were critical of a second appointment made a few months earlier (Dr Shah had not applied for this post) there was considerable disagreement on whether a Ph.D in crop physiology plus ten years in agronomy was a suitable qualification for a post advertised as requiring a $\mathrm{Ph} . \mathrm{D}$ in agronomy plus ten years' experience.

The almost obsessively narrow nature of this issue unfortunately provided a rather simple escape mechanismbetter procedures in recruitment and promotion in ICAR. Unfortunate for two reasons- first because it is by no means clear that Indian science, already much stifled by its reverence for degrees, authority and seniority, needs even more rigid adherence to paper qualifications (a third of all who responded to the committee's questionnaire said that promotion should be based on seniority, without reference to merit). The best science doesn't always reveal itself to the best qualified. Second, because there is still no real sign that the Indian government sees more than administrative changes as necessary as a consequence of Dr Shah's suicide and this report. As the technical advisers bluntly put it, intellectual corruption exists at all levels; much more than changes in selection procedures are needed to eliminate it. The origins of this corruption are not difficult to find-they lie in the surfeit of bureaucracy, concentration of power at headquarters, a gross oversupply of graduates some of whom seem to acquire their degree only for matrimonial purposes, the shortage of money, the poor quality of technical help and the lack of diversity of opportunity within Indian science.

None of these problems is easily solved, but they are all potentially soluble. Mrs Gandhi, by being Minister for Science and Technology herself, is expressing a national faith that science and technology can still help India. She is in a powerful position to take bold steps to reduce mistrust and discontent amongst the scientific community, and she should take radical action.

We regret the poor quality of the paper on which last week's Nature was published. Continuity of paper supply has posed a continual problem for us, but we are doing everything possible to stabilise the situation. 